\title{
Comparison of Cognitive Changes in Patients With Alzheimer's and Parkinson's Disease
}

\author{
Yaakov Stern, PhD; Marcus Richards, PhD; Mary Sano, PhD; Richard Mayeux, MD
}

- Objective.-To compare cognitive changes in the dementias of Parkinson's disease (PD) and Alzheimer's disease (AD).

Design.-Case series, group comparisons.

Setting.-Ambulatory care referral center.

Patients. - Consecutive sample of 14 patients with PD dementia and 27 with probable $A D$ matched for overall intellectual function using a mental status test, as well as 14 nondemented PD and 12 mild probable AD patients, similarly matched for overall intellectual function. All demented patients met Diagnostic and Statistical Manual, Revised Third Edition, criteria for dementia.

Main Outcome Measures.-Performance on a battery of neuropsychological tests assessing verbal and nonverbal memory, vèrbal fluency, and constructional ability.

Results.-Nondemented and demented patients with PD performed worse than their probable AD comparison groups on verbal fluency and visuospatial tasks. Cognitive changes attributable to dementia were similar in PD and probable AD but were not identical. The patients with probable AD demonstrated more marked change in memory performance with delay.

Conclusions.-Our findings suggest that when dementia occurs in PD it is overlaid on cognitive changes that already exist in nondemented patients but that the dementing process in PD involves systems other than those responsible for cognitive change in nondemented PD patients. We hypothesize that in most cases, dementia in PD involves changes in a nondopaminergic neurotransmitter system but is not due to concomitant AD.

(Arch Neurol. 1993;50:1040-1045)

$T^{1}$

he extent to which the dementias of Parkinson's disease

(PD) and Alzheimer's disease (AD) overlap remains controversial. As Brown and Marsden ${ }^{1}$ point out, some investigators have concluded that the two dementias differ in etiology and phenomenology, ${ }^{2}$ while after reviewing the same literature, others remain unconvinced. ${ }^{13,4}$ We contrasted performance of demented patients with $\mathrm{AD}$ and $\mathrm{PD}$ on a battery of neuropsychological tests. The assumption

\footnotetext{
Accepted for publication March 26, 1993.

From the Departments of Neurology (Drs Stern, Sano, and Mayeux) and Psychiatry (Drs Stern and Mayeux), Columbia University College of Physicians and Surgeons, and the Gertrude H. Sergievsky Center (Drs Stern, Richards, Sano, and Mayeux), New York, NY.

Reprint requests to Neurological Institute, 710 W 168th St, New York, NY 10032 (Dr Stern).
}

underlying this approach is that differences in the pattern of neuropsychological changes may suggest ways in which the pathology underlying the dementias differs. Several extensive reviews of comparative studies exist. ${ }^{1-5}$

Several methodological issues are important for comparative studies of neuropsychological performance in $\mathrm{AD}$ and PD dementia. Both groups should meet the same criteria for dementia. The diagnosis of dementia should not be exclusively based on neuropsychological testing because any potential test performance differences between the two groups would lead to differential patterns of diagnosis. The two groups should be matched for dementia severity, although the most appropriate matching strategy is not immediately apparent.. Typically, matching has been based on brief mental status examinations that presumably assess general intellectual function or overall dementia severity. Few comparative studies of probable $\mathrm{AD}(\mathrm{pAD})$ and $\mathrm{PD}$ dementia have met these methodological criteria. ${ }^{6-13}$

For this study, we administered a range of neuropsychological tests assessing verbal and nonverbal memory, verbal fluency, and constructional ability to patients with pAD and PD dementia. To diagnose dementia in both PD and pAD, we used Diagnostic and Statistical Manual, Revised Third Edition (DSM-III-R), criteria for primary degenerative dementia, ${ }^{14}$ which emphasize functional as well as cognitive impairment, and the NINCDS-ADRDA guidelines for the diagnosis of $\mathrm{pAD},{ }^{15}$ which stress the process of ruling out other potential causes of dementia. The diagnosis of dementia was determined separately from the neuropsychological battery we used.

We explored two different strategies for matching dementia severity. First, the pAD and PD dementia groups were matched for overall intellectual function using a mental status examination. Because items on a mental status test tap aspects of cognition differentially affected by one disease over another, using total scores might result in unequal matching. We therefore explored an alternate matching strategy: matching the groups' performance on a specific neuropsychological test, in this case a test of memory.

An additional methodological concern has not been addressed by previous investigators. It is well recognized that neuropsychological changes occur in nondemented PD patients, including word-finding difficulties, visuospatial dysfunction, and problems with some memory and executive dysfunction. ${ }^{4,16-18}$ Even after adequate matching for dementia severity in $\mathrm{PAD}$ and $\mathrm{PD}$, differences in neuropsychologi- 
cal test performance might actually be a function of cognitive changes that already exist in nondemented PD patients and that are separate from the dementing process. To clarify this issue, we administered the same test battery to nondemented, moderately cognitively impaired PD and mild pAD patients, similarly matched for overall intellectual function or memory scores.

We hypothesized that neuropsychological test performance in PD dementia represents a combination of cognitive changes that predate the onset of dementia and are present in most nondemented patients, along with qualitatively different cognitive changes that are unique to the presence of dementia. While we predicted that the latter changes would be similar to those seen in AD, we were interested in identifying any areas of divergence since these might be informative for understanding the basis of dementia in PD.

\section{PATIENTS AND METHODS}

Patients with $\mathrm{PD}(\mathrm{n}=54)$ and $\mathrm{pAD}(\mathrm{n}=58)$ provided informed consent, underwent neuropsychological testing, and were used as a pool from which to select groups for comparisons of neuropsychological test performance in $\mathrm{PAD}$ and $\mathrm{PD}$. Not all patients were used for comparisons because some could not be matched (as will be described) and some had incomplete data.

Diagnosis of idiopathic PD was made by a neurologist based on the presence of two of the cardinal signs of resting tremor, bradykinesia, postural disorder, and rigidity, along with careful elimination of other potential parkinsonian syndromes. For demented PD patients, the diagnostic signs of $\mathrm{PD}$ were required to have been present for at least 1 year prior to the onset of intellectual decline.

Prior to the analyses described herein, the records of the patients with PD were reviewed by three investigators (Y.S., M.S., and R.M.) who had followed them clinically and in previous studies. For each patient, the clinicians reached a consensus dementia diagnosis using DSM-III-R criteria for dementia ${ }^{14}$ and NINCDS-ADRDA criteria for $\mathrm{pAD},{ }^{15}$ with the obvious exception of their having had a concomitant illness, PD. Key considerations were whether patients had sufficient memory and cognitive impairment for this diagnosis and whether their cognitive impairment resulted in social or occupational dysfunction. Twenty of the PD patients met these criteria for dementia. The patients with pAD met DSM-III-R criteria for dementia as well as NINCDS-ADRDA criteria for $\mathrm{pAD}$. All subjects were free of other neurological illness or medical conditions that could potentially be responsible for cognitive change or dementia.

\section{Procedures}

The following neuropsychological test battery was administered to all subjects.

Modified Mini-Mental State Examination (mMMSE).-The mMMSE $^{19}$ was given as a test of general intellectual function. This modification of the Mini-Mental State Examination ${ }^{20}$ has a maximum score of 57 , and reliability and validity have been established. $^{21}$

Selective Reminding Test (SRT).- In this list-learning task, ${ }^{22}$ the subject attempts to recall a list of 12 verbally presented words. After each recall attempt, the subject is reminded only of the words that were not recalled and is asked to again attempt to recall the entire list. This procedure is repeated for a total of 12 recall trials. The SRT performance measures included (1) total recall: the total of all words recalled on all trials, with a maximum score of 144 (12 words $\times 12$ trials); (2) long-term retrieval: the total of words considered to have been retrieved from long-term storage--words recalled on two successive trials (without an intervening reminder) were counted on those two and all following trials in which they were recalled; and (3) intrusions: total instances of recalling words that were not on the test list-these words were corrected the first time they were reported by the patient and were scored as intrusion errors each subsequent time they were reported (for intrusions, a higher score indicates poorer performance).
Wechsler Memory Scale.-Three subtests of this scale ${ }^{23}$ were administered: (1) logical memory: the subject attempts to recall verbatim the content of two paragraphs of thematic material; (2) visual reproduction: the subject attempts to draw three pictures from memory after viewing each for 10 seconds; and (3) associate learning: three trials are given to learn 10 word-pairs. For the logical memory and visual reproduction subtests, a 15-minute delayed retest was given with no warning. Change scores, consisting of the difference between the immediate and delayed recall scores, were calculated for each subtest as indexes of change in recall performance with delay.

Controlled Oral Word Association Test (CFL).-For this test, ${ }^{24}$ the subject is required to name as many words as possible beginning with the letters $/ c /, / f /$, and $/ l /$, with 1 minute allowed for each letter.

Category Naming.-Patients were required to generate words for three categories: animals, food, and clothing. One minute was allowed for each category.

Rosen Drawing Test.-This test ${ }^{25}$ consists of 15 designs that the subject is asked to copy. Designs range in difficulty from simple figures, such as circles and squares, to overlapping and threedimensional figures. Qualitative aspects of the constructions are scored; parkinsonian features such as tremor do not influence scoring.

\section{Statistical Analysis}

Analytic Strategy.-Two sets of comparisons of neuropsychological test performance were made. In the first set, matching was based on mMMSE scores and in the second set, groups were matched on performance on SRT total recall. In both sets, demented $\mathrm{PD}$ and $\mathrm{pAD}$ patients were contrasted, and then patients with $\mathrm{pAD}$ were contrasted with nondemented, mildly impaired PD patients. This latter match was possible for two reasons: some of the nondemented PD patients had cognitive impairment that did not affect their social and occupational function; others had cognitive impairment that affected mMMSE scores but did not meet the described criteria for dementia.

Because of the large number of variables involved, multivariate analysis of covariance (MANCOVA) was used for between-group contrasts of performance on the neuropsychological battery. Since MANCOVAs require complete data for all measures analyzed, patients with missing data on any test were eliminated. A total of eight PD (two nondemented; six demented) and 19 pAD patients were eliminated for this reason.

The matching procedure for the mMMSE scores was as follows. Since we did not want the same patients with pAD used in both comparisons and since the potential pool of pAD patients who could be matched by mMMSE score to nondemented PD patients was smaller, selection for this comparison took priority. A range of mMMSE scores that contained the maximal number of nondemented PD patients and PAD patients was identified. There were 14 nondemented PD patients and 12 pAD patients in the mMMSE score range of 43 to 52 ; there were 18 nondemented PD patients who scored too high on the mMMSE to be included in this comparison. Following this procedure, the remaining patients with $\mathrm{pAD}$ were contrasted with the demented PD patients to ensure similarity of mMMSE scores and demographic variables, and matching was determined to be adequate.

The second set of comparisons was similar, but matching was based on performance on memory measure (total recall on theSRT). The procedure used to derive the groups was equivalent to that described for matching by mMMSE score range.

Statistical Techniques.-Comparability of the groups on each matching variable was assessed using Student's $t$ tests. For the MANCOVAs, the individual neuropsychological test scores were used as dependent variables, and patient group was a betweengroup factor (two levels). Hotelling's $T^{2}$ statistic was selected to test the multivariate group effect. To increase the accuracy of group matching, variables on which the patient groups were matched were also used as covariates. Kolmogorov-Smirnov goodness-of-fit tests were applied to each test score to check for departures from normality. Where a significant departure was found for any variable, that 


\begin{tabular}{|c|c|c|c|c|c|}
\hline \multicolumn{6}{|c|}{$\begin{array}{l}\text { Table 1.-Comparison of Demented Parkinson's } \\
\text { Disease (PD) and Probable Alzheimer's Disease (pAD) } \\
\text { Groups Matched for Modified Mini-Mental State } \\
\text { Examination (mMMSE) Scores }\end{array}$} \\
\hline \multirow[b]{2}{*}{ Variables* } & \multicolumn{2}{|c|}{ PD $(n=14)$} & \multicolumn{2}{|c|}{$\mathrm{pAD}(\mathrm{n}=27)$} & \multirow[b]{2}{*}{$\boldsymbol{P}$} \\
\hline & Mean & SD & Mean & SD & \\
\hline Age, $y$ & 71.1 & 8.7 & 67.3 & 8.7 & NSt \\
\hline Education, y & 15.1 & 4.4 & 14.0 & 4.2 & NSt \\
\hline Duration, $y$ & 10.1 & 10.3 & 3.7 & 1.5 & $\ldots$ \\
\hline $\mathrm{mMMSE}$ & 38.1 & 6.1 & 35.1 & 6.1 & NSt \\
\hline $\begin{array}{l}\text { SRT } \\
\text { Total recall } \\
\text { Long-term retrieval } \\
\text { Intrusions }\end{array}$ & $\begin{array}{r}44.9 \\
15.3 \\
2.2\end{array}$ & $\begin{array}{r}13.0 \\
9.5 \\
3.5\end{array}$ & $\begin{array}{r}49.8 \\
21.0 \\
4.9\end{array}$ & $\begin{array}{r}16.2 \\
14.9 \\
6.2\end{array}$ & $\begin{array}{l}\text { NS } \\
\text { NS } \\
\text { NS }\end{array}$ \\
\hline $\begin{array}{l}\text { WMS } \\
\text { Logical memory } \\
\text { Vistual reproduction } \\
\text { Associate learning }\end{array}$ & $\begin{array}{l}3.2 \\
0.2 \\
7.1\end{array}$ & $\begin{array}{l}2.0 \\
0.4 \\
2.2\end{array}$ & $\begin{array}{l}3.0 \\
1.3 \\
7.1\end{array}$ & $\begin{array}{l}1.6 \\
1.4 \\
2.8\end{array}$ & $\begin{array}{l}\text { NS } \\
.014 \\
\text { NS }\end{array}$ \\
\hline CFL & 6.2 & 2.6 & 9.3 & 5.0 & .005 \\
\hline Category Naming & 6.6 & 2.3 & 10.1 & 4.1 & .001 \\
\hline Rosen Drawing Test & 6.5 & 3.3 & 9.4 & 2.6 & .001 \\
\hline $\begin{array}{l}\text { Immediate-delayed recall } \\
\text { WMS logical memory } \\
\text { WMS visual } \\
\text { reproduction }\end{array}$ & 0.2 & 0.4 & 2.4 & 1.4 & .023 \\
\hline
\end{tabular}

*SRT indicates Selective Reminding Test; WMS, Wechsler Memory Scale; CFL, Controlled Oral Word Association Test; and NS, not significant.

$+P$ values are from $t$ tests. Remaining $P$ values are from univariate $F$ tests following a multivariate analysis of variance comparing all remaining variables simultaneously.

variable was omitted from the multivariate analysis of variance, and a Mann-Whitney $U$ test was used to assess group differences.

\section{RESULTS \\ Disease Characteristics of PD Patients}

All but one patient with PD included in the analyses were optimally treated with dopamine replacement therapy for at least 1 month prior to testing; the remaining patient was receiving no dopamine replacement therapy. Four (three nondemented and one demented) patients were receiving anticholinergic medication. Modal score on the Hoen and Yahr scale was 3 . One (demented) patient had a score of 1 , seven (six nondemented, one demented) had a score of 2 , and one (demented) had a score of 4 .

\section{Match for General Intellectual Function}

pAD and Demented PD Patients.-There were 14 demented PD patients who were matched with 27 patients with pAD for general intellectual function on the mMMSE. Means and SDs for these demographic variables and each neuropsychological test score for the two groups are presented in Table 1. Preliminary $t$ tests revealed no differences between these two groups in age, education, or mMMSE level.

A Kolmogorov-Smirnov test revealed a skewed distribution with the Wechsler visual memory score. A MannWhitney test revealed a significant group difference on this variable $(P=.014)$. The remaining variables were subjected to MANCOVA, with age, education, and MMMSE as covariates.

The multivariate test revealed an overall group difference with these variables $\left(T^{2}=0.87, P=.011\right)$. Corresponding univariate $\mathrm{F}$ tests, with $(1,36) d f$, showed that the following
Table 2. Comparison of Nondemented PD and PAD Groups Matched for mMMSE Scores*

\begin{tabular}{|c|c|c|c|c|c|}
\hline \multirow[b]{2}{*}{ Variables* } & \multicolumn{2}{|c|}{ PD $(n=14)$} & \multicolumn{2}{|c|}{ pAD $(n=12)$} & \multirow[b]{2}{*}{$\boldsymbol{P}$} \\
\hline & Mean & SD & Mean & SD & \\
\hline Age, y & 59.9 & 8.9 & 73.2 & 6.7 & $.001 t$ \\
\hline Education, y & 13.9 & 2.5 & 15.3 & 3.6 & NSt \\
\hline Duration, $y$ & 6.6 & 3.4 & 3.2 & 1.9 & $\ldots$ \\
\hline mMMSE & 47.6 & 2.7 & 46.4 & 2.4 & NSt \\
\hline \multicolumn{6}{|l|}{ SRT } \\
\hline Total recall & 75.0 & 15.5 & 59.6 & 15.8 & NS \\
\hline Long-term retrieval & 46.2 & 21.1 & 25.7 & 17.2 & NS \\
\hline Intrusions & 1.2 & 2.6 & 3.2 & 3.0 & .012 \\
\hline \multicolumn{6}{|l|}{ WMS } \\
\hline Logical memory & 5.9 & 2.5 & 3.8 & 1.2 & .038 \\
\hline Visual reproduction & 5.4 & 3.2 & 4.1 & 3.0 & NS \\
\hline Associate learning & 11.6 & 3.2 & 7.3 & 3.0 & .03 \\
\hline CFL & 9.9 & 3.3 & 13.7 & 5.4 & .002 \\
\hline Category Naming & 15.9 & 4.3 & 14.3 & 3.5 & NS \\
\hline Rosen Drawing Test & 10.4 & 2.0 & 12.2 & 1.5 & .052 \\
\hline \multicolumn{6}{|l|}{ [mmediate-delayed recall } \\
\hline WMS logical memory & 1.9 & 1.2 & 3.2 & 1.5 & .02 \\
\hline WMS visual reproduction & 2.8 & 2.9 & 3.8 & 3.0 & NS \\
\hline
\end{tabular}

* See Table 1 for expansion of abbreviations.

$+P$ values are from $t$ tests. Remaining $P$ values are from univariate $F$ tests following a multivariate analysis of variance comparing all remaining variables simultaneously.

variables contributed to this effect: $\mathrm{CFL}(\mathrm{F}=9.01, P=.005)$, Category Naming $(\mathrm{F}=20.76, P<.001)$, and Rosen Drawing Test $(\mathrm{F}=14.23, P=.001)$. In all cases, performance was significantly poorer in the PD group.

Change scores between immediate and delayed Wechsler Memory Scale were also analyzed. The visual reproductions change score was significantly skewed. A Mann-Whitney test showed a greater decline in patients with $\mathrm{PAD}$ than patients with PD for this test $(P=.03)$, although a floor effect for immediate visual reproductions in PD patients should be kept in mind (Table 1). The $t$ tests revealed greater change in logical memory for $\mathrm{pAD}$ than PD patients $(t=2.36, P=.023)$.

In summary, demented $P D$ patients showed impaired verbal fluency and constructional ability relative to patients with pAD matched for overall intellectual ability. Performance on short-term memory tests was comparable except for visual reproduction, but patients with $\mathrm{pAD}$ showed more marked change in recall performance with delay on the logical memory test.

pAD and Nondemented PD Patients.-There were 14 nondemented PD patients who were matched with 12 patients with $\mathrm{pAD}$ for general intellectual function on the mMMSE. Means and SDs for these demographic variables and each neuropsychological test score for these two groups are shown in Table 2 . Preliminary $t$ tests revealed no differences in education or mMMSE level for these two groups. However, patients with pAD were significantly older $(t=4.22, P<.001)$.

All variables were normally distributed and were subjected to MANCOVA, with mMMSE, age, and education as covariates. The multivariate group effect was significant $\left(T^{2}=3.14, P=.007\right)$. Corresponding univariate $\mathrm{F}$ tests, with $(1,21) d f$, showed that the following variables contributed to this effect: SRT intrusion errors ( $F=7.62, P=.012)$, logical memory ( $\mathrm{F}=4.92, P=.038)$, associate learning $(\mathrm{F}=5.41, P=.03)$, 


\begin{tabular}{|c|c|c|c|c|c|}
\hline \multicolumn{6}{|c|}{$\begin{array}{l}\text { Table 3.-Comparison of Demented PD and Mild pAD } \\
\text { Groups Matched for SRT Scores* }\end{array}$} \\
\hline \multirow[b]{2}{*}{ Variables* } & \multicolumn{2}{|c|}{ PD $(n=14)$} & \multicolumn{2}{|c|}{ pAD $(n=24)$} & \multirow[b]{2}{*}{$\boldsymbol{P}$} \\
\hline & Mean & $S D$ & Mean & SD & \\
\hline Age, $y$ & 71.1 & 8.7 & 71.6 & 7.9 & NSt \\
\hline Education, y & 15.1 & 4.4 & 14.1 & 4.2 & NSt \\
\hline Duration, $y$ & 10.1 & 10.3 & 3.8 & 1.6 & \\
\hline \multicolumn{6}{|l|}{ SRT } \\
\hline Total recall & 44.9 & 13.0 & 44.0 & 13.6 & NSt \\
\hline Long-term retrieval & 15.3 & 9.5 & 15.4 & 9.6 & NSt \\
\hline Intrusions & 2.6 & 3.5 & 5.0 & 6.5 & NSt \\
\hline mMMSE & 38.1 & 6.1 & 37.2 & 7.6 & NS \\
\hline \multicolumn{6}{|l|}{ WMS } \\
\hline Logical memory & 3.2 & 2.0 & 3.3 & 1.6 & NS \\
\hline Visual reproduction & 0.2 & 0.4 & 2.0 & 2.7 & .008 \\
\hline Associate learning & 7.1 & 2.2 & 6.8 & 3.2 & NS \\
\hline CFL & 6.2 & 2.6 & 8.4 & 3.8 & .047 \\
\hline Category Naming & 6.6 & 2.3 & 10.0 & 4.2 & .007 \\
\hline Rosen Drawing Test & 6.5 & 3.3 & 9.5 & 2.7 & .006 \\
\hline \multicolumn{6}{|l|}{ Immediate-delayed recall } \\
\hline WMS logical memory & 1.4 & 1.3 & 2.8 & 1.3 & .002 \\
\hline WMS visual reproduction & 0.2 & 0.4 & 1.8 & 2.7 & .018 \\
\hline
\end{tabular}

* See Table 1 for expansion of abbreviations.

$+P$ values are from $t$ tests. Remaining $P$ values are from univariate $F$ tests following a multivariate analysis of variance comparing all remaining variables simultaneously.

CFL ( $F=13.08, P=.002)$, and Rosen Drawing Test $(F=4.25$, $P=.052$ ). For the memory tests, performance was better in the patients with $\mathrm{PD}$ than in patients with $\mathrm{pAD}$. However, the reverse was true for the CFL test and the Rosen Drawing Test.

The Wechsler memory change scores were normally distributed. The $t$ tests revealed a significantly greater decline in logical memory scores $(t=2.5, P=.02)$ in patients with $\mathrm{PAD}$.

In summary, nondemented PD patients showed superior short-term memory performance compared with pAD patients on three of four tests (considering the fewer intrusion errors on the SRT). Patients with pAD showed more change in recall performance with delay on the logical memory test. However, the relatively impaired Rosen Drawing Test and CFL scores found in demented PD patients were also present in the nondemented group.

\section{Match for Verbal Memory}

pAD and Demented PD Patients.-There were 14 demented PD patients who were matched with 24 patients with pAD on the total recall scale of the SRT (Table 3). Preliminary $t$ tests revealed no differences in age, education, or total SRT recall between these two groups.

An abnormal distribution was found for the visual reproduction score. A Mann-Whitney $U$ test revealed a poorer score for this test in PD patients $(P=.008)$. The remaining variables were subjected to a MANCOVA, using age, education, and $\mathrm{MMMSE}$ as covariates. The multivariate test for the group effect was significant $\left(T^{2}=0.82, P=.028\right)$. Corresponding univariate $F$ tests, with $(1,33) \mathrm{df}$, showed that the following variables contributed to this effect: $\mathrm{CFL}(\mathrm{F}=4.25, P=.047)$, Category Naming ( $\mathrm{F}=8.35, P=.007)$, and Rosen Drawing Test $(\mathrm{F}=8.78, P=.006)$. For all three of these tests, performance was poorer in $\mathrm{PD}$ than $\mathrm{pAD}$ patients.

The change score for visual reproductions was skewed. A Mann-Whitney $U$ test revealed a greater decline in this test

\begin{tabular}{|c|c|c|c|c|c|}
\hline \multicolumn{6}{|c|}{$\begin{array}{l}\text { Table 4.- Comparison of Nondemented PD and pAD } \\
\text { Groups Matched for SRT Scores* }\end{array}$} \\
\hline \multirow[b]{2}{*}{ Variables* } & \multicolumn{2}{|c|}{ PD $(n=12)$} & \multicolumn{2}{|c|}{ pAD $(n=12)$} & \multirow[b]{2}{*}{$\boldsymbol{P}$} \\
\hline & Mean & SD & Mean & SD & \\
\hline Age, y & 60.0 & 5.8 & 60.3 & 4.7 & NSt \\
\hline Education, $y$ & 14.1 & 3.4 & 14.3 & 3.7 & NSt \\
\hline Duration, y & 6.2 & 3.8 & 3.0 & 1.3 & $\ldots$ \\
\hline \multicolumn{6}{|l|}{ SRT } \\
\hline Total recall & 68.2 & 9.5 & 66.6 & 9.3 & NSt \\
\hline Long-term retrieval & 38.7 & 14.0 & 34.8 & 14.1 & NSt \\
\hline Intrusions & 1.3 & 1.9 & 4.2 & 3.4 & $.025 t$ \\
\hline $\mathrm{mMMSE}$ & 48.8 & 4.3 & 39.9 & 5.6 & .001 \\
\hline \multicolumn{6}{|l|}{ WMS } \\
\hline Logical memory & 5.2 & 2.1 & 3.4 & 1.4 & .036 \\
\hline Visual reproduction & 4.9 & 2.8 & 2.7 & 1.9 & .039 \\
\hline Associate learning & 10.0 & 3.1 & 6.7 & 1.6 & .006 \\
\hline CFL & 9.1 & 2.1 & 12.4 & 4.7 & .048 \\
\hline Category Naming & 14.9 & 4.3 & 12.4 & 3.9 & NS \\
\hline Rosen Drawing Test & 10.3 & 1.9 & 10.8 & 2.9 & NS \\
\hline \multicolumn{6}{|l|}{ Immediate-delayed recall } \\
\hline WMS Iogical memory & 1.8 & 1.3 & 2.6 & 1.7 & NS \\
\hline WMS visual reproduction & 2.7 & 2.7 & 2.3 & 1.8 & NS \\
\hline
\end{tabular}

*See Table 1 for expansion of abbreviations.

$+P$ values are from $t$ tests. Remaining $P$ values are from univariate $F$ tests following a multivariate analysis of variance comparing all remaining variables simultaneously.

score in patients with pAD $(P=.018)$. A $t$ test revealed a greater decline in logical memory in $\mathrm{PAD}$ than $\mathrm{PD}$ patients $(t=3.26, P=.002)$.

In summary, demented PD patients performed more poorly than the group with pAD on Wechsler Memory Scale visual reproduction, two verbal fluency tasks (CFL and Category Naming), and Rosen Drawing Test. Other tests of short-term memory yielded comparable performance. There was more marked change in recall performance with delay in the group with $\mathrm{pAD}$ on the logical memory test.

pAD and Nondemented PD Patients.-There were 12 nondemented PD patients who were matched with 12 patients with $\mathrm{pAD}$ for performance on the total recall score of the SRT and for age (Table 4). Preliminary $t$ tests revealed no differences in age, education, or SRT total recall between these two groups.

All variables were normally distributed and were subjected to MANCOVA, with the SRT total recall, education, and age as covariates. A highly significant group effect was found $\left(T^{2}=13.84, P<.001\right)$. Corresponding univariate $\mathrm{F}$ tests, with $(1,19) d f$, showed that the following variables contributed to this effect: $m M M S E$ total score $(F=17.05, P<.001)$, SRT intrusions ( $\mathrm{F}=5.89, P=.025)$, logical memory $(\mathrm{F}=5.08, P=.036)$, associate learning $(\mathrm{F}=9.56, P=.006)$, and visual reproductions $(\mathrm{F}=4.90, P=.039)$. Performance was poorer in the group with pAD, while CFL performance was poorer in the PD group $(\mathrm{F}=4.48, P=.048)$. Wechsler memory change scores were normally distributed. No group differences were found.

In summary, scores for the mMMSE and all memory tests were poorer in the group with $\mathrm{pAD}$, but patients with PD still had poorer CFL performance than those with $\mathrm{pAD}$.

\section{COMMENT}

Matching severity of dementia in two different diseases is complex. To begin with, sources of functional impairment 
are potentially different in the two patient groups. The primary defining feature of $\mathrm{pAD}$ and its resulting functional incapacity is cognitive change. In PD, motor signs are a major cause of functional disability, but the DSM-III-R diagnostic criteria for dementia require functional impairment resulting from cognitive deficit. This can result in diagnostic errors. We attempted to minimize this possibility by carefully considering severity of motor disability, extensively questioning patients and informants, and investigating functional skills that should remain relatively unaffected by motor changes of PD.

An additional complication in matching PAD and PD dementia is the well-documented cognitive change that occurs in nondemented PD patients. By definition, these patients do not meet DSM-III-R criteria for dementia. Still, some nondemented PD patients' cognition was sufficiently impaired to enable matching on overall intellectual level with patients with mild pAD.

\section{Matching Based on mMMSE}

Our results clearly demonstrate that visuospatial and verbal fluency performances are affected in both demented and moderately impaired nondemented PD patients. In contrast, there seems to be a qualitative difference in the pattern of memory performance as PD patients become demented.

The CFL and Rosen Drawing Test scores in the nondemented PD group were worse than those in the mild pAD group. These findings parallel previously described cognitive changes in nondemented patients with PD. Poor performance on visuospatial tasks such as the Rosen Drawing Test and on verbal fluency tasks have often been reported in $P D,{ }^{26-29}$ Our findings strengthen the results of the other studies since they were based on comparisons with $\mathrm{pAD}$ patients and not merely with normal controls. Demented PD patients also had impaired verbal fluency and constructional ability relative to their matched group with pAD. Similarly, even though it is putatively a test of memory, relative performance on the visual reproduction subtest of the Wechsler Memory Scale also probably can be accounted for by the strong visuospatial component of this test. In this case, nondemented PD patients performed similarly to their pAD comparison group, while demented PD patients performed worse than their comparison group. Thus, the relative performance deficits on these tests might best be viewed as reflecting preexisting cognitive changes of $\mathrm{PD}$ on which the later dementia of PD is superimposed. This concept is reinforced by a supplementary analysis where we used MANCOVA to contrast neuropsychological test performance in the more mildly affected pAD patients (ie, mMMSE range of 43 to 52) with that in nondemented PD patients whose mMMSE scores were too high to be included in this analyses, ie, nondemented PD patients with mMMSE scores above 52. Even in this group of intact PD patients, CFL scores were significantly worse than those in the pAD group, while Rosen Drawing Test scores were comparable.

In contrast, our results suggest a qualitative difference in memory performance between nondemented and demented PD patients. When nondemented PD patients' performance on memory tests was compared with their mMMSE-matched pAD group, the group with pAD performed more poorly on aspects of the SRT, logical memory, and paired associate learning. When demented $P D$ and $\mathrm{PAD}$ patients were compared, performance on all immediate memory tests was similar (except for the visuospatially loaded visual memory test, where PD patients performed more poorly). These data suggest that rather than a simple quantitative worsening of memory, a qualitative change in memory dysfunction occurs as PD patients become demented.

Nondemented PD patients made fewer intrusion errors on the SRT, but they performed as poorly as their matched $\mathrm{pAD}$ group on the total recall and long-term retrieval measures of the SRT. Other groups have also reported memory difficulties in nondemented PD patients when they compared them with healthy controls. ${ }^{10,30-32}$ Problems with list-learning procedures, such as the SRT, have been attributed to difficulties organizing material, ${ }^{4,30}$ but this issue is not settled. Still, there are qualitative differences between nondemented and demented PD patients' performance on the SRT that may reflect different causal mechanisms. Specifically, when compared with the nondemented PD patients, there were more intrusion errors in the pAD group, while demented PD patients were comparable with their pAD comparison group in the number of intrusion errors made. Finally, both logical memory and paired associate learning performance was comparable with pAD patients in the demented PD patients but not in the nondemented ones.

\section{Matching on the Basis of Verbal Memory}

Matching $\mathrm{pAD}$ and $\mathrm{PD}$ patients on SRT performance was intended to more directly calibrate the two groups on a single key feature of dementia, as opposed to the mMMSE, which includes items that tap many cognitive functions. When demented PD and $\mathrm{PAD}$ patients were matched on SRT total recall, other aspects of immediate memory were also comparable. However, demented PD patients still performed worse on verbal fluency tasks, drawing, and a visual memory task requiring drawing. General intellectual function, assessed by the mMMSE, was comparable.

In contrast, when nondemented PD patients were matched to those with pAD based on SRT performance, all other memory tests still yielded poorer performance in the group with $\mathrm{pAD}$. Also, the patients with $\mathrm{pAD}$ made more intrusion errors on the SRT itself than did the patients with PD. Furthermore, mMMSE performance was poorer in the patients with $\mathrm{PAD}$. This reinforces the idea that in $\mathrm{PD}$, poor SRT performance is not associated with general cognitive decline or even decline across several memory domains. Despite better memory performance and higher mMMSE scores, the patients with PD performed worse on CFL than the patients with $\mathrm{pAD}$.

These findings complement those obtained by matching for mMMSE. In both sets of comparisons, patients with PD have difficulty with construction and verbal fluency tasks whether or not they are demented, suggesting that these deficits are present in nondemented patients and are independent of the dementing process. However, the qualitative difference between demented and nondemented PD patients in memory performance was again noted.

\section{Change in Memory Performance With Delay}

Change scores, consisting of the difference between immediate and delayed recall, were evaluated for three memory tests: logical memory, associate recall, and visual reproduction. Change scores on the visual reproduction test are not meaningful because of the extremely poor baseline performance in the patients with PD. In both comparisons of demented $\mathrm{pAD}$ and PD patients, those with $\mathrm{pAD}$ had higher change scores on the logical memory test, indicating more marked change in recall performance with delay, even 
though the immediate memory measures were comparable. This suggests that while many aspects of memory loss are comparable in demented PD and pAD patients, change scores demonstrate a feature of memory loss that is more severe in $\mathrm{pAD}$. This tendency for patients with $\mathrm{pAD}$ to show more marked change in memory performance with delay than demented PD patients has been described previously. ${ }^{11}$

In the two comparisons using nondemented PD patients, the general trend was also for a greater change in memory performance with delay in the patients with $\mathrm{pAD}$, which is consistent with comparisons in the demented group.

\section{Effect of Age}

There was a large disparity in the ages of the nondemented PD patients and their pAD comparison group. Weaddressed this disparity by including age as a covariate in our analyses. Despite their younger age, the nondemented PD patients performed more poorly than their pAD comparison group on several tasks, and similarly on the SRT. In addition, when patients were matched on SRT performance, no age differences were noted, and results complemented those seen from the mMMSE match. We concluded that the age disparity did not influence our observations.

\section{Dementia in PD and PAD}

Our findings suggest that when dementia occurs in PD, it is overlaid on cognitive changes that already exist in nondemented patients. A widespread assumption, which has been supported by studies of parkinsonism induced by MPTP (1-methyl-4-phenyl-1,2,3,6-tetrahydropyridine), ${ }^{33}$ is that these preexisting changes are due to loss of dopaminergic innervation of the basal ganglia, although this issue is far from settled. ${ }^{34,35}$ While the data examined herein are cross-sectional and do not directly assess changes in cognition as patients with PD become demented, we propose that as dementia emerges, there is a qualitative shift in the pattern of cognitive deficits in PD, with substantial broadening and worsening of memory dysfunction. The qualitativeshift may be associated with new changes in a nondopaminergic system. One possibility is that the new cognitive features associated with dementia result from the development of an ADlike illness. This would explain the overall similarity in the pattern of neuropsychological performance in the two diseases after accounting for the preexisting PD-related cognitive changes. However, although similarities far outweighed differences in our comparisons, our observation of more marked change in memory performance with delay in pAD emphasizes the repeated observation that the dementias in these two diseases are not completely homologous. ${ }^{6,-13}$ On the whole, our results most strongly support the idea that the qualitative shift in cognition as dementia emerges in PD represents the onset of degeneration in a nondopaminergic neurotransmitter system but do not support the concept that dementia in PD is due to concomitant AD pathology. Onelikely candidate is exacerbation of changes in the cholinergic system since changes in this system can be present in PD dementia even when pathological changes of $\mathrm{AD}$ are not. ${ }^{36}$

This study was supported by federal grants AG02802, AG07232, and AG08702, by The Robertson Memorial Gift for Alzheimer's Disease, and by The Parkinson's Disease Foundation, New York, NY.

\section{References}

1. Brown RG, Marsden CD. 'Subcortical dementia': the neuropsychological evidence. Neuroscience. 1988;25:363-387.

2. Cummings IL. Subcortical dementia: neuropsychology, neuropsychia- try and pathophysiology. Br / Psychiatry. 1986:149:682-697.

3. Whitehouse PJ. The concept of subcortical dementia: another look. Ann Neurol. 1986;19:1-6.

4. Dubois B, Boller F, Pillon B, Agid Y. Cognitive deficits in Parkinson's disease. In: Boller R, Grafman J, eds. Handbook of Neuropsychology, V. Amsterdam, the Netherlands: Elsevier Science Publishers; 1991:195-240.

5. Mahler ME, Cummings JL. Alzheimer's disease and the dementia of PD: comparative investigations. Alzheimer Dis Assoc Disord. 1990;4:133149.

6. Bayles KA, Tomoeda CK. Confrontation naming impairment in dementia. Brain Lang. 1983;19:98-114.

7. Mayeux R, Stern Y, Rosen J, Benson DF. Is 'subcortical dementia' a recognizable clinical entity? Ann Neurol. 1983;14:278-283.

8. Freedman $M$. Oscar BM. Selective delayed response deficits in Parkinson's and Alzheimer's disease. Arch Neurol. 1986;43:886-890.

9. Pillon B, Dubois B, Lhermitte F, Agid Y. Heterogeneity of cognitive impairment in progressive supranuclear palsy: Parkinson's disease and Alzheimer's disease. Neurology. 1986;36:1179-1185.

10. Sahakian BJ, Morris RG, Evendien IL, et al. A comparative study of visuospatial memory and learning in Alzheimer's-type dementia and Parkinson's disease. Brain. 1988;111:695-718.

11. Heikala EL, Laulumaa V, Soininen H, Riekkinen PJ. Recall and recognition memory in patients with Alzheimer's and Parkinson's diseases. Ann Neurol. 1988;24:214-217

12. Sullivan EV, Sagar HJ, Gabrieli JDE, Corkin S, Growdon IH. Different cognitive profiles on standard behavioral tests in Parkinson's disease and Alzheimer's disease. I Clin Exp Neuropsychol. 1989:11:799-820.

13. Huber SJ, Shuttleworth EC, Freidenberg DL. Neuropsychological differences between the dementias of Alzheimer's and Parkinson's diseases. Arch Neurol. 1989:46:1287-1291.

14. American Psychiatric Association, Committee on Nomenclature and Statistics. Diagnostic and Statistical Manual of Mental Disorders, Revised Third Edition. Washington, DC: American Psychiatric Association; 1987.

15. McKhann $G$, Drachman D, Folstein $M$, et al. Clinical diagnosis of Alzheimer's disease: report of the NINCDS-ADRDA Work Group under the auspices of the Department of Health and Human Services task force on Alzheimer's disease. Neurology. 1984;34:939-944.

16. Stern $Y$. The basal ganglia and intellectual function. In: Schneider l, ed. Basal Ganglia and Behavior: Sensory Aspects of Motor Functioning. Toronto, Ontario: Hans Huber; 1987:169-174.

17. Brown RG, Marsden CD. Cognitive function in Parkinson's disease: from description to theory. Trends Neurosci. 1990;13:21-28.

18. Raskin SA, Borod JC, Tweedy J. Neuropsychological aspects of Parkinson's disease. Neuropsychol Rev. 1990;1:185-221.

19. Mayeux R, Stern Y, Rosen J, Leventhal J. Depression, intellectual impairment and Parkinson disease. Neurology. 1981:31:645-650.

20. Folstein MF, Folstein SE, McHugh PR. 'Mini-Mental State,' a practical method for grading the cognitive state of patients for the clinician. / Psychiat Res. 1975;12:189-198.

21. Stern Y, Sano M, Paulson J, Mayeux R. Modified Mini-Mental State Examination: validity and reliability. Neurology. 1987;37(suppl 1):179.

22. Buschke $\mathrm{H}$, Fuld PA. Evaluating storage, retention, and retrieval in disordered memory and learning. Neurology. 1974;24:1019-1025

23. Wechsler D. A standardized memory scale for clinical use. I Psychol. 1945:19:87-95

24. Benton AL, Hamsher KD. Multilingual Aphasia Examination. lowa City: University of lowa; 1976.

25. The Rosen Drawing Test. Bronx, NY: Veterans Administration Medical Center; 1981

26. Stern $Y$, Mayeux R, Rosen J. Contribution of perceptual motor dysfunction to construction and tracing disturbances in Parkinson's disease. I Neurol Neurosurg Psychiatry. 1984;47:983-994.

27. Mattison R, Mayeux R, Rosen 1, Fahn S. 'Tip-of-the-tongue' phenomenon in Parkinson's disease. Neurology. 1982;32:567-570.

28. Lees AJ, Smith E. Cognitive deficits in the early stages of Parkinson's disease. Brain. 1983;106:257-270.

29. Gotham AM, Brown RG, Marsden CD. 'Frontal' cognitive function in patients with Parkinson's disease 'on' and 'off' levodopa. Brain. 1988;111: 299-321.

30. Taylor AE, Saint-Cyr JA, Lang AE. Frontal lobe dysfunction in Parkinson's disease. Brain. 1986:109:845-883.

31. Levin BE, Llabre MM, Weiner WJ. Cognitive impairment associated with early Parkinson's disease. Neurology. 1989;39:557-561.

32. Cooper IA, Sagar HI, Jordan N, Harvey NS, Sullivan E. Cognitive impairment in early, untreated Parkinson's disease and its relationship to motor disability. Brain. 1991;114:2095-2122.

33. Stern $Y$, Langston J. Intellectual changes in patients with MPTPinduced parkinsonian syndrome. Neurology. 1985;35:1506-1509.

34. Dubois B, Danze $F$, Pillon B, Cusimano $G$, Lhermitte $F$, Agid $Y$. Cholinergic-dependent cognitive deficits in Parkinson's disease. Ann Neurol. $1987 ; 22: 2-30$

35. Dubois B, Pillon B, Lhermitte F, Agid Y. Age-induced cognitive disturbances in Parkinson's disease. Neurology. 1990;40:38-41.

36. Perry $\mathrm{RH}$, Tomlinson BE, Candy $M$, et al. Cortical cholinergic deficit in mentally impaired parkinsonian patients. Lancet. 1983;309:789-790. 